\title{
IMPROVING MODERN INTELLIGENCE ANALYTICAL CAPABILITY
}

\author{
Željko Gajić \\ Ministry of Defense of the Republic of Serbia
}

The modern era is characterized by globalization, fast technology development and innovation. Dynamic environment, demanding customers, competitive opponents and business partners, a dramatic increase of data quantity are some of biggest problems modern analysts are faced with. An advanced form of methodology and technology should provide a vigorous and fast examination of a large amount of different types of data. A technological solution is important for strengthening analytical capabilities, but human resources are still crucial.

Key Words: Business analysis, Intelligence, Big Data, Forecasting, Uncertainty

\section{Introduction}

$T$ he role of analytics in business and intelligence is more important than ever. Military strategies have always instructed us that good intelligence can provide different solutions, deter an enemy attack or prepare forces for an active defense and counter attack. There is a chapter in the best known ancient military strategy dedicated to intelligence and the role of spies. The main task of intelligence is mentioned in the statement: "The greatest victory is that which requires no battle" [1]. In business, understanding of environment and competitive capabilities is crucial for making strategies, plans and decisions.

The modern era is characterized by globalization, fast technology development and innovation. The nature of contemporary security and economy relations is affected by emergence of new, non-traditional and non-state actors who are taking advantage of benefits of modern era and tend to create a more unstable, hard-to-predict situation. Reducing uncertainty in those circumstances is a very difficult task, which is why both the intelligence and business community are trying to find a way to improve understanding of important actors, events and processes. That is of greater value than collecting and analyzing classified and open sources information, and it can take many forms and involve many types of analytical products. The aim is to learn more about what is known, what remains unknown, and which processes and events can jeopardize our strategy and plan [2].

The dynamic environment and increasingly unstable and competitive situation stimulate intelligence analytics to find new methods and tools for increasing confidence in their product by providing timely, precise and accurate products for decision makers. 


\section{Competitive Intelligence}

Modern business environment requires constant evaluation of conditions in which the business is conducted, as well as market research and monitoring of capacities and intentions of competitors. For this purpose, and apart from constant improvement of one's own capabilities, it is necessary to make decisions, based on timely and good information, that contribute to more efficient business and better market positioning against competition.

The modern age, characterized by the globalization process and rapid development of technology, provides great opportunities and facilitates the monitoring of business environment. That situation offers the possibility of simpler access to information, raw materials, business partners and buyers from all around the world, whereas, on the other hand, the business management becomes susceptible to risks of consequences related to events and processes carried out in other business areas or parts of the world. Besides, mass use of PCs, various personal devices, smart phones, Internet etc. in the last few decades resulted in massive increase of number of users. They change their habits, more or less, and adapt to a new, virtual world. This way, huge number of generated data may provide managers with new knowledge relevant for decision making. At the same time, there is a necessity to discover new ways to adapt to conditions under which it is becoming more and more difficult to correctly analyze information, identify risks, important processes and trends and forecast changes and significant events of decisive importance for selecting business strategies and policies.

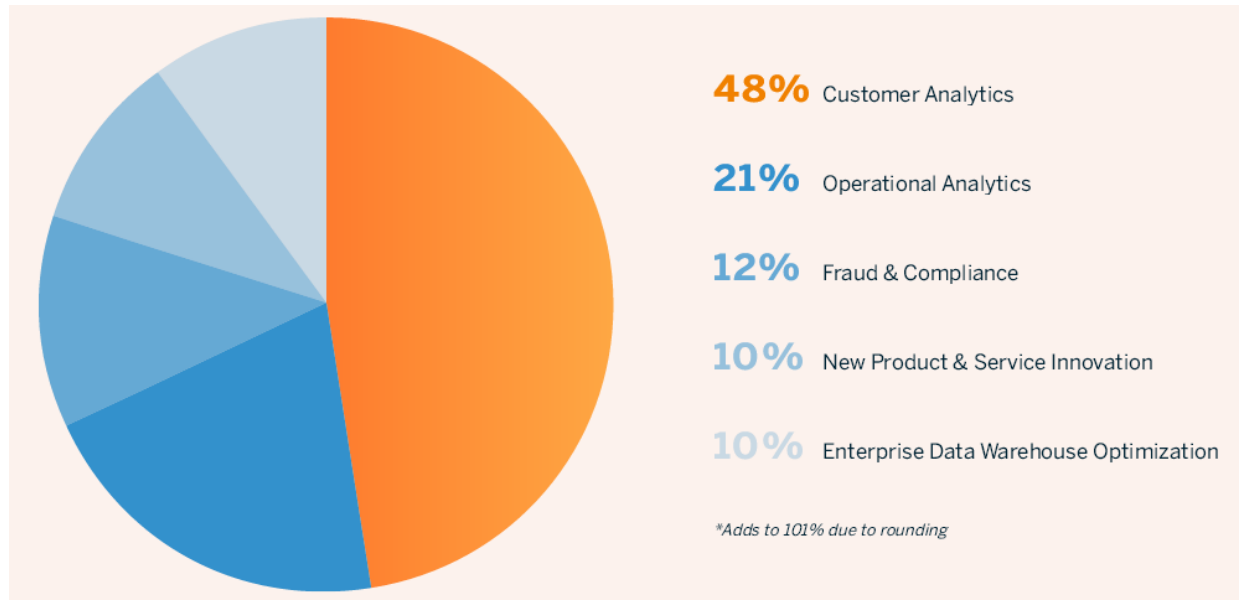

Figure 1 - Assessment of Information Type Ratio (Datameer, 2016)

There are various definitions of competitive intelligence, but they all basically refer to gaining information related to a certain type of business important to a company profile. This can be achieved by searching public available data or interviewing people with knowledge about needed information. The primary research is very useful for developing broad context and awareness about current situation on the market and for detecting 
trends. However, for a wider insight it is necessary to carefully analyze existing data, make objective assessments and forecast market trends with respect to the competitors. In this manner the decision makers are able to foresee the upcoming market developments, adjust their business strategy and allocate resources for a more effective approach in the future. For all the reasons mentioned above, the need for collection and processing of information about customers and competitors will be in even higher demand [3].

In the era of rapid, hard-to-predict changes, this great challenge could be overcome if the problem is approached in a comprehensive manner, by using experience and results of scientific research in this area. There are some disciplines that should be able to offer an answer based on scientific principles regarding the issue of making low-risk business decisions. For that reason, development of business analytics is very important as it encompasses possibilities of informational technologies, managers' demands and challenges of doing business both in the present and in the future. A significant number of governments and private organizations are interested in developing analytical capabilities and forecasting technics and methods. There are organizations and agencies specialized in gathering and processing information, preparing evaluation and analysis, as well as predicting future developments. They use technics and methods which are based on experience and scientific principles, while analysts are provided special training during which they gain necessary knowledge and abilities in order to make more accurate and realistic predictions.

\section{Intelligence Challenges}

Even though the modern era introduced numerous opportunities, it also brought certain problems and difficulties that hinder the collection and processing of data. Availability of contemporary communication technologies makes it easier to collect data but harder to choose quality information relevant for brainstorming and decision making. Contemporary analytics is therefore posed with a problem of defining priorities properly, classification of available information for their reliability and quality of new knowledge. In addition, analysts should be prepared to handle a huge number of various and different pieces of available information, best described by terms Big Data and Internet of Things.

Big Data is a phenomenon which occurred as a result of a large increase of available data in digital form, that are incurred by a variety of personal and industrial electronic devices, social networks and others. However, there is more to it than just a quantitative increase. It is also a qualitative change of the way in which new knowledge is created, which leads to major changes in economy and business [4]. A vast number of available data, largely unnecessary and of suspicious value, impose the need to improve the existing methodology for their collecting, storing, processing and analysis. Current philosophy aimed at collecting data should be adapted in the sense that more attention in the earliest stages of the cycle is devoted to selection of necessary data, choosing the best methods for collecting information, as well as improving the analysis and presenting the results.

The Big Data phenomenon affects not only the commercial sector, but the functioning of the state institutions and agencies as well. The large increase in the number of users, devices and data is extremely important for the defense and national security sector. The development of technology, reduction of costs and increase of the number of services have 
led to high availability of information to government agencies and the private sector, but have also increased the risk of security threats, especially non-traditional ones. Publicly available information relevant to security are also available to various extremist or terrorist organizations, groups and individuals. In addition, the existing infrastructure, databases, as well as data exchange and processing are all subject to, and may be exposed to unauthorized access and even modification, which may lead to major problems in the functioning of institutions, critical infrastructure and the like. "Technological advances also create the potential for increased systemic fragility as foreign governments and non-state actors attempt to leverage new and evolving technologies to press their interests" [5].

Security situation in the world is becoming more complex and challenging than before. For those tasked with preventing and responding to local, national, and global public threats to security, the amount of potentially useful data is enormous. This can be overcome by using modern software tools and techniques for data collection from multiple sources and advance analytics methods aimed to provide timely intelligence and objective insight [6].

Besides changing the conditions in which organizations operate, technology development has also led to increasing demands by users of reports, analysis and assessments. Regardless of whether they are owners or directors of companies, directors of various sectors or users of intelligence information in state institutions, the level of demand has increased. The users are more educated and have more means of data collection, therefore further efforts must be made in order to preserve the exclusivity of information. Customers and their requests are constantly changing, which is why analysts should establish and keep the integrity for every one of them [7]. Intelligence consumers seek a more in-depth analysis, whose focus is on methodology, assumption and forecast. Providing a high level of credibility of an analytical product in the eyes of the costumers is a long standing goal [8]. There is a higher degree of competitiveness between private companies and agencies that offer collecting and processing data services.

The changes in the private and government sectors are due to be implemented in financially constrained circumstances. While the need to preserve the competitiveness is crucial for the survival of companies, investing in data collection and protection of infrastructure and data is often not sufficient. All this imposes the need for constant review of the efficiency and effectiveness of the existing system, as well as exploring ways to improve the possibilities for data collection and processing in modern conditions.

There is both financial and security concern regarding that type of programs. The European Union will invest 120 billion euros over the next five years into creating a "digital single market". That initiative is aimed to design "free flow of data within the EU" with financing emerging technologies such as Internet of Things (loT), 5G and quantum computing. Sharing data and cross-border cooperation in the EU is a good idea in theory, but security concerns as well as member states' law limitations and willingness make it far-fetched in practice [9].

\section{Business Analysis in Complex Environments}

Business analysis is deeply affected by the Big Data phenomenon. Modern business conditions contribute to the rapid development of some disciplines that should be able to offer an answer based on scientific principles regarding the issue of how to make a business decision with less risk. 
There are three main types of business analytics that offer various solutions descriptive analytics, predictive analytics and prescriptive analytics [10]. At the initial level, there is a phase of reporting about certain processes as well as analyzing the reasons why the results of production, sale, etc. are the way they are. This part of descriptive analytics contains data and reports about current indicators important for business management, such as utilization of capacities, availability of stocks etc. The next phase of the predictive analytics encompasses an assessment about what may happen, as well as probability of certain events significant for business management. The most complex is prescriptive analytics, which should develop various scenarios and simulations in order to properly evaluate the results and consequences of decisions made.

Commercial sector makes use of the new technologies' potential, especially in monitoring costumers' behavior and consuming routines. Based on modern sophisticated algorithm and advance software, a marketing expert can explore, analyze, explain and provide understanding of customers' behavior and consumption pattern. As a result, they can predict costumers' wishes, suggest appropriate approach to the client and prepare customized offers.

\section{Contemporary Intelligence Analysis}

The ultimate goal of national intelligence is the same as it was in the past: to suppress the attack by gathering information about the enemy. Intelligence of today has to produce new insights and knowledge about real and potential threats by collecting and analyzing political, economic and military information. In the past it mainly consisted of collecting secret information, but nowadays intelligence covers broader topics and means for creating understanding about important subject of political and military interest. That paradigm shift is inspired, among other things, by effects of globalization, technological development and appearance of many non-traditional and non-state threats.

The complexity of modern analytic tasks, sources, disciplines, costumers and forms of reports can be seen from the next figure [11].

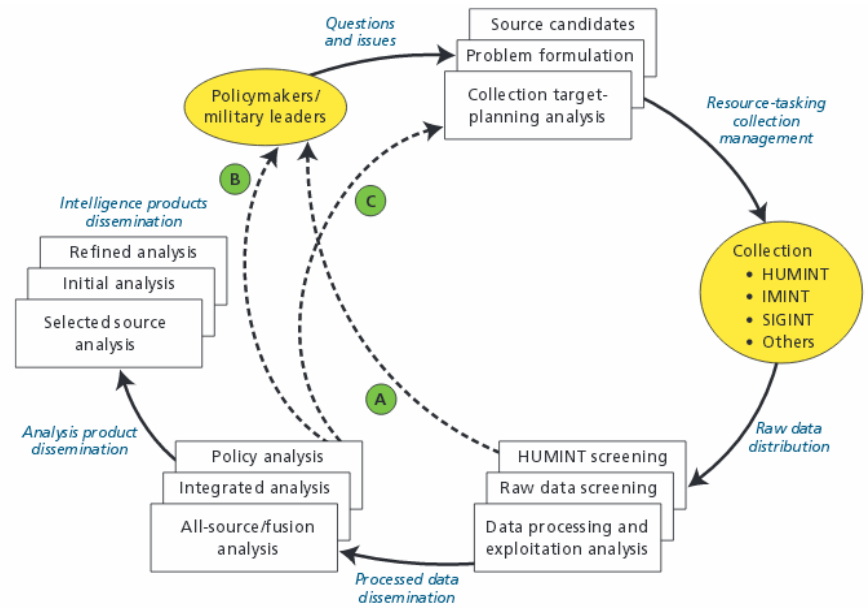

Figure 2 - An Illustrative Intelligence Cycle (Treverton, 2008) 
One of the most important characteristics of current and future intelligence is utilization of flow and accessibility of enormous amount of digital data. Software acquisition and implementation of commercial solutions about collection, storage and data manipulation present a starting point for modern intelligence. Since more data and information are generated by users and social networks, more investments are aimed at mobile personal platforms, which increases opportunity for collection and analysis. Enormous flows of data create other challenges. The old fashion defense intelligence was based on seeking secret information about the enemy which was very hard to find. Nowadays, it is expected that intelligence agencies manage enormous quantities of data using data and computer science, statistics and other related disciplines. Big Data enforced the development of advanced analytical tools with intuitive interfaces and visualization solutions which can be applied in defense intelligence. Massive use of portable devices and sensors in various fields (industrial, cars, navigation, home appliance...) and emerging communication capacities and numerous link channels forced scientific research and development in intelligence community (IC). However, the real opportunity for defense is monitoring research processes and achievements in the commercial sector, as well as using and customizing developed modules and solutions instead of dictating requirements. [4]

\section{Innovative Action for More Agile Business and Intelligence Analytics}

Modern analytics faces numerous challenges. Customer requirements are becoming more complex, and the circumstances of data collecting and processing demand improvement of existing and search for new methods and techniques of analytical processing. Making analysis and assessments is very difficult, bearing in mind that the companies and agencies are faced with changes which are very rapid and getting harder to predict.

In order for the agencies, organizational units and analysts to be better prepared for the challenges of current and future environment, it is necessary to take measures to ensure a more efficient functioning and realization of the goals set under ever demanding conditions.

\section{Organizational Measures}

Government intelligence agencies took a lot of actions in order to increase efficiency of the intelligence process. There are no unique organizational schemes, scopes and responsibilities of departments of an intelligence agency. The resources and assigned tasks determine the agency structure which is to provide the most effective management and balanced use of resources in times of limited finances and requirements growing in complexity.

The larger organizations are often faced with problems of centralization and duplication of lines of communication, resource engagement and reaching common understanding. An organizational structure has to provide a possibility for better synchronization, cooperation and much tighter integration. 
That problem is characteristic for huge organizations, such as the US Intelligence Community, which consists of 17 agencies with more than 100.000 employees (about 20.000 analysts) [12]. Managing that enterprise is a big challenge. After the terrorist attack on 9/11, a specially formed commission concluded that elements of IC need to be coordinated better. The conclusion led to establishment of the Office of the Director of National Intelligence (with about 1.500 employees). The Office is run by the Director of National Intelligence with the main purpose to coordinate national intelligence elements and control more than $65 \$$ billion overall budget for intelligence activities. However, a mere reorganization without a comprehensive strategy and a clear plan will not bring expected results.

Intelligence community in the United States is constantly introducing innovations which aim to increase efficiency and functioning in Big Data era. The future of intelligence analysis is much more than shifting of organizational boxes [12]. The impact of technological development and growing threats forced Central Intelligence Agency (CIA) to create a new directorate for the first time in 50 years - Directorate of Digital Innovation [13]. Similarly, the National Security Agency (NSA) has initiated a Trusted Systems Research Group, and has partnered with North Carolina State University to fund a new Laboratory for Analytic Science. Some projects involve organizations outside intelligence community and are conducted by public and private research activities, such as: Defense Advanced Research Projects Agency (DARPA); Intelligence Advanced Research and Projects Activity (IARPA); Advanced Research Projects Agency-Energy (ARPA-E); and the national laboratories [8]

\section{Prioritization of Resources}

The main task of leadership is to provide sustainable human and material resources and accordingly prioritized tasks and activities. This is extremely complicated in dynamic environment and budget constraints. In combination with inadequate organizational solutions, it may lead to a loss of resources and reduced capabilities. For example, the changes in the organizational structure of the Defense Intelligence Agency at the end of the 20th century had mixed results. It is very important to find an appropriate approach and carefully consider potential cut in resources in context of missions and security environment [14]. About that time (the end of the Cold War), the Director of National Intelligence stated that intelligence agencies achieved about 23 percent reduction, many stations were closed and a number of collectors and analysts was reduced [15]. Consequently, those decisions had a big impact on functioning of intelligence community today.

It may be deducted from the statement of former Commander of the US European Command and NATO Commander General Philip Breedlove how important it is to timely identify course that could significantly change our understanding and knowledge of processes important for security. Namely, General Breedlove analyzed the reasons for the surprise effect on the United States by the performance of Russia in Ukraine in 2014. General considers that at that time the US intelligence community was engaged in several regions for a longer period, and that their resources were engaged far from Russia for several decades (the Middle East, Afghanistan, the first and the second war in Iraq, the fight against terrorism after the attacks of Al Qaeda on the US on 11 September 2001 ...). Those were the decisions made, and priorities were set accordingly. Russia was monitored mainly on the strategic level 
(nuclear weapons), and the operational and tactical level of military capabilities' development was monitored with reduced capacity. It is only now that significant analytical capacities are directed towards the Russian Federation, while decisions about engaging other intelligence capacities are still pending. [16]

\section{Procedural and Methodological Measures}

A traditional intelligence process involves collecting data from different types of sensors or sources. In that system analysts have to find, collect and compile pieces of information. Information, which is more or less manually accumulated, then has to be analyzed. According to a research, at least $50-80$ percent of analyst work is related to searching and preparing information before using them for analysis [17]. A large amount of data makes the system ineffective and an analyst becomes overwhelmed with diminished possibility to make sense of it.

The problem should be minimized by developing IT architecture and software which provides an analyst with more time to focus on hard, key problems. This would enable understanding patterns of interested processes and actions, discovering links among objects and identifying abnormal functions and activities. Better system integration will increase analytical efficiency and improve the quality of analytical products. Enhanced cooperation between collectors and analysts, as well as constant innovation will improve efficiency of collecting and analytical accuracy [18].

The traditional analytical process is focused on targeted collection and single-source analysis, but some information may not be properly examined at early stages without being associated and integrated with more data. An advanced form of methodology and modern technology should provide a vigorous and fast examination of a large quantity of different types of data. Moreover, it will be possible to automatically identify trends, data overlap and intersection. An analyst will find it easier to identify when levels rise above normal values and discover indicators of a potential threat [19].

\section{Technological Measures}

Defense budgets are under constant fiscal pressures, which forces leadership to create a climate for a more effective use of resources and setting the goals according to priority. Cooperation with commercial sector provides the opportunity that some of these tool and technique are used in defense intelligence. The leaders of technological research and development are no longer exclusively founded by the government and a clear line in that field doesn't exist anymore [18]. Elements and systems that civilian hightech companies offer are in some critical military capabilities more advanced than that of traditional defense industry [20].

A very interesting example of cooperation between the government and private sector is the Intelligence Advanced Research Projects Activity - IARPA, agency created to enhance research and development in the US intelligence community. One of IARPAs main tasks is the cooperation with private sector and academic community through funding joint projects. On of IARPAs topic of interest is how to maximize understanding of massive and dynamic scope of data in a timely manner [21]. Similarly, the Defense 
Advanced Research Projects Agency - DAPRA, with an almost $\$ 3$ bn budget, run many innovative projects. One of the newest, successfully developed and tested projects is integration of low-cost software run on Android platforms for close air support. By using that system on a tablet computer, a helicopter missile was launched on a target seven times faster than in a current procedure and it offered an analyst and tactical commander more time to prioritize targets and make decisions. This way airstrikes can be generated in less time and with greater precision using less ammunition [22].

\section{Human Resource Measures}

A technological solution is important for strengthening analytical capabilities, but human resources are still crucial. Investing in a better and modern technological solution will produce a result only if both collectors and analysts are capable of using them. In order to build necessary skills it is important to constantly invest in people. Improving analyst performance will ensure an adequate response of intelligence in a dynamic environment.

Comprehensive improvement of a training program should be based on the current set of skills and expected level of performance. It has to be adjusted with responsibility level and constantly updated. The US Defense Intelligence Agency (DIA) prepared different types of courses for their employees. An extensive formal training is provided for beginners in their first six months of employment. A special course is developed for middle level analysts, while senior rank executives attend short, three day refresher course [18].

When employing new personnel, it is necessary that the chosen applicants meet the current and future requirements with adequate preparation. In an increasingly complex world, the DIA realized that they should occasionally employ people with non-traditional skills in order to be able to overcome the situations in which traditional tools and methodologies cannot be fully applied [18]. Desirable critical analytical skill can be defined based on previous experiences. The important ones are motivation and commitment in resolving problems; ability to separate important from unimportant issues, as well as facts from assumptions. The most important characteristic is the ability to break the problem into smaller parts, analyze the validity of available data and their impact on the problem solution.

An important characteristic of a good analyst is the ability to present a problem in a way it was recognized in the past, as well as to determine principles that reoccur and could be used for resolving a concrete problem. Apart from that, it is an imperative to be able to separate personal experience and opinion from the available facts. In a dynamic environment an analyst has to explore different types of information, and to seek beyond the arguments that support his view. Those who are willing to revise their point of view due to changes and new information will provide better results. Superior analysts are mostly pragmatic, open-minded, they carefully seek, select and check information. They are curious and able to analyze data from different fields gained from different sources.

Carefully prepared training can improve those skills. It is important to note that teamwork boosts analytical performance [23]. A good team organization and quality interaction among motivated members grants good results. Analysts have to be able to express their opinion 
without fear, they have to listen and accept different, and opposite opinions if they contribute to better analyses of the situation and precision in assessments. But if there is a lack of communication and slow dynamics, imposing opinions and unhealthy competition, the results of prediction and assessment could be wrong [24]. Bearing in mind all mentioned above, it can be concluded that the structure of a team is very important and that a good preparation, interaction and teamwork lead to a better analytical product.

In order to yield a better assessment, apart from individual abilities and characteristics of analysts, it is important to constantly upgrade analytical procedures. For a more efficient work, development and improvement of the assessment quality it is necessary to monitor its results in the future, i.e. to what degree the assumptions materialize. Even if time shows that the results are not good enough, it is important to study initial data and identify reasons for making a wrong assessment. Without additional analyses and conclusions, the process cannot be upgraded and reaching high level of analysis is almost impossible.

There are other authors who support this concept. For example, prominent Richard Hauer wrote about methods and technics that can help in overcoming problems in intelligence analytics. He considers that it is very hard to find a good way to define adequate evaluation criteria for probability of the development, which leads to a problem when performing a complex analysis. Bearing that in mind, he points out the need to improve analytic technics and create new "analytic culture", different from the current, with improved coordination among analysts, continued testing and questioning of the initial hypothesis, improved selection and training [12].

\section{Conclusion}

In very complex conditions, characterized by fast and very hard to predict environment, business and defense intelligence should be agile and adaptable to new circumstances. The role of leadership is crucial in that process, in a way that they should understand the needs for constant changes and improvements of performance.

Business and defense analysts are faced with similar challenges. Dynamic environment, demanding customers, competitive opponents and other business partners, a dramatic increase of data quantity are some of biggest problems modern analysts are faced with. They cannot deal with those challenges without adaptable methodology, sophisticated algorithms and tools and high skilled personnel. The topics cover broad and complex political, cultural and religious context, and the analyses, assessments and forecasts have to be supported and compared with experts outside the subject matter. When faced with numerous traditional and non-traditional, state and non-state risks and threats, making priorities is even more important than in the past. Limited resources and constant budget pressure result in closer cooperation between commercial and government managers.

The role of leadership is critical: a success or failure in the future is deeply related to and determined by the quality of today's decisions. Vital decisions about national security are and will be guided by, among others, intelligence and different forms of analytical products. Business and intelligence analyses have even more importance in the information age than in the past. 
In the time of global news channels and abundance of information available on personal devices, analysts do not have a comfortable role of briefing on current events. It is expected that they offer objective assessments, precise, in-depth analyses and more accurate forecasts. That is possible by increasing the analytical capacity, which is achieved by engaging actively in the planning process, guiding a more focused collection, developing innovative and suitable methods and tools, as well as by conducting long term researches in close cooperation with scientific and academic institutions and commercial industry.

Technology innovation and modern analytical techniques cannot provide the desired outcome of analytical process on their own. In the end, there will always be skill and trained analysts with experience, commitment and passion. Improving their capabilities for fast and constant adaption to changeable environment is the ultimate goal. Continual search for the right balance among human competencies and advantages of new technologies is the answer and a way how modern business and intelligence analytics can be prepared even better for current and future challenges.

\section{Bibliography}

[1] "Original The Art of War translation (not Giles)," Sonshi.com - Your Source for Sun Tzu's The Art of War. [Online]. Available: http://www.sonshi.com/original-the-art-of-war-translation-not-giles.html. [Accessed: 08-May-2016].

[2] Thomas Fingar, Reducing Uncertainty: Intelligence Analysis and National Security. Stanford, California: Stanford Security Studies, 2011.

[3] "Big Data: A Competitive Weapon for the Enterprise," Datameer. [Online]. Available: http://www.datameer.com/wp-content/uploads/2015/09/State_of_the_Industry.pdf.

[Accessed: 03-May-2016].

[4] P. B. Symon and A. Tarapore, "Defense Intelligence Analysis in the Age of Big Data," National Defense University Press. [Online]. Available:

ttp://ndupress.ndu.edu/Media/News/tabid/7781/Article/621113/defense-intelligence-analysis-in-theage-of-big-data.aspx. [Accessed: 02-May-2016].

[5] "National Intelligence Strategy - 2014." [Online]. Available:

https://www.dni.gov/files/documents/2014_NIS_Publication.pdf. [Accessed: 01-May-2016].

[6] B. Akhgar, G. B. Saathoff, H. R. Arabnia, R. Hill, A. Staniforth, and P. S. Bayerl, Application of Big Data for National Security: A Practitioner's Guide to Emerging Technologies, 1 edition. Waltham, MA: Butterworth-Heinemann, 2015.

[7] M. Petersen, I. Lukes, J. Ehrman, and H. Peake, "What I Learned in 40 Years of Doing Intelligence Analysis for US Foreign Policymakers," Cent. Intell. AGENCY Wash. DC Cent. STUDY Intell., vol. 55, no. 1, 2011.

[8] Anne Daugherty Miles, "The U.S. Intelligence Community: Selected Cross-Cutting Issues," Congressional Research Service, Apr. 2016.

[9] Mary-Ann Russon, "Is the EU's idea to create a digital single market for all 'Internet of Things' data a clever one?," International Business Times UK, 26-Apr-2016. [Online]. Available: http://www.ibtimes.co.uk/eu-investing-120bn-create-giant-internet-things-what-about-security-risk1556873. [Accessed: 08-May-2016].

[10] Vujošević Mirko and Vujošević Dušan, "Business analytics: A challenge to managers, researchers and software engineers," Info $M$, vol. 13, no. 50, pp. 4-14, 2014. 
[11] G. F. Treverton and C. B. Gabbard, Assessing the tradecraft of intelligence analysis. Santa Monica, Calif: RAND Corporation, 2008.

[12] "The Black Budget: Explore top secret U.S. intelligence funding," Washington Post. [Online]. Available: http://www.washingtonpost.com/wp-sv/special/national/black-budget/. [Accessed: 29-May-2016].

[13] Richards J. Heuer, "Limits of intelligence analysis," Orbis, vol. 49, no. 1, pp. 75-94, 2006.

[14] "U.S. Intelligence in a Transforming World," Council on Foreign Relations, CIA Director, March13, 2015. [Online]. Available: http://www.cfr.org/intelligence/us-intelligence-transformingworld/p36271. [Accessed: 01-May-2016].

[15] J. A. McDonnell, "Adopting to a Changing: Environment," Def. Intell. Agency Hist. Res. Div. Wash. DC, 2013.

[16] Wanlund, William., "Intelligence Reform," $C Q$ Researcher by $C Q$ Press. [Online]. Available: http://library.cqpress.com/cqresearcher/cqresrre2015052900. [Accessed: 07-May-2016].

[17] J. E. Barnes, "Q\&A with Gen. Philip Breedlove, Top Commander of U.S. and Alliance Forces in Europe," WSJ. [Online]. Available: http://blogs.wsj.com/brussels/2016/05/03/qa-with-genphilip-breedlove-top-commander-of-u-s-and-alliance-forces-in-europe/. [Accessed: 03-May-2016].

[18] S. Lohr, "For Big-Data Scientists, 'Janitor Work' Is Key Hurdle to Insights," The New York Times, 17-Aug-2014.

[19] Catherine Johnston, Elmo C. Wright, and Jessica Bice, Jennifer Almendarez, and Linwood Creekmore, "Transforming Defense Analysis," National Defense University Press. [Online]. Available: http://ndupress.ndu.edu/Media/News/tabid/7781/Article/621117/transforming-defense-analysis.aspx. [Accessed: 02-May-2016].

[20] C. P. Atwood, "Activity-Based Intelligence: Revolutionizing Military Intelligence Ana," National Defense University Press. [Online]. Available:

http://ndupress.ndu.edu/Media/News/tabid/7781/Article/581866/activity-based-intelligencerevolutionizing-military-intelligence-analysis.aspx. [Accessed: 04-May-2016].

[21] Adam Jay Harrison, "DOD 2.0: High Tech Is Eating the Pentagon | U.S. Naval Institute." [Online]. Available: http://www.usni.org/magazines/proceedings/2016-02/dod-20-high-tech-eating-pentagon. [Accessed: 01-May-2016].

[22] Aaron Boyd, "IARPA funding brings ideas 'from disbelief to doubt,"' Federal Times. [Online]. Available: http://www.federaltimes.com/story/government/it/2016/05/06/iarpa-funding-brings-ideasdisbelief-doubt/84018872/. [Accessed: 07-May-2016].

[23] Erin Smith, "US Armed Forces can now control airstrikes from an Android Tablet app | Technology," The news Hub. [Online]. Available: https://www.the-newshub.com/technology/androidtablet-delivers-airstrikes-in-record-time. [Accessed: 08-May-2016].

[24] L. Ungar, B. Mellors, V. Satopää, J. Baron, P. Tetlock, J. Ramos, and S. Swift, "The good judgment project: A large scale test," AAAI Technical Report,(FS-12-06), 2012.

[25] B. Mellers, E. Stone, P. Atanasov, N. Rohrbaugh, S. E. Metz, L. Ungar, M. M. Bishop, M. Horowitz, E. Merkle, and P. Tetlock, "The psychology of intelligence analysis: drivers of prediction accuracy in world politics," J. Exp. Psychol. Appl., vol. 21, no. 1, pp. 1-14, Mar. 2015. 